\title{
Effect of tumor size on prognosis of node- negative lung cancer with sufficient lymph node examination and no disease extension
}

This article was published in the following Dove Press journal:

OncoTargets and Therapy

5 February 2016

Number of times this article has been viewed

\author{
Yang Zhang ${ }^{1,2}$ \\ Yihua Sun ${ }^{1,2}$ \\ Haiquan Chen ${ }^{1-4}$ \\ 'Department of Thoracic Surgery, \\ Fudan University Shanghai Cancer \\ Center, ${ }^{2}$ Department of Oncology, \\ Shanghai Medical College, Fudan \\ University, ${ }^{3}$ Shanghai Chest Hospital, \\ Shanghai Jiao Tong University, \\ ${ }^{4}$ Institutes of Biomedical Sciences, \\ Fudan University, Shanghai, \\ People's Republic of China
}

Background: The effect of tumor size on the prognosis of node-negative non-small-cell lung cancer (NSCLC) might be biased by missed lymph node metastasis and local disease extension.

Methods: We investigated 2,260 patients with N0M0 NSCLC in the Surveillance, Epidemiology and End Results (SEER) database diagnosed from 1998 to 2012. Eligible patients had $\geq 18$ lymph nodes examined and no disease extension. Tumor size was classified as T1a $(0-10 \mathrm{~mm})$, T1b (11-20 mm), T1c (21-30 mm), T2a (31-40 mm), T2b (41-50 mm), T3 (51-70 mm), and T4 (>70 mm).

Results: The 5-year cancer-specific survival (CSS) rates for T1a, T1b, T1c, T2a, T2b, T3, and T4 patients were $85.6 \%, 84.4 \%, 79.9 \%, 77.9 \%, 70.0 \%, 63.0 \%$, and $61.7 \%$, respectively. The 5-year overall survival (OS) rates for T1a, T1b, T1c, T2a, T2b, T3, and T4 patients were $77.8 \%$, $74.1 \%, 68.2 \%, 64.5 \%, 58.7 \%, 53.2 \%$, and $57.3 \%$, respectively. Using $\mathrm{T} 1 \mathrm{a}$ as the reference, the hazard ratio generally increased with tumor size in the multivariate analysis of CSS and OS, with the exception of T4 patients.

Conclusion: After adjusting for lymph node examination and disease extension, tumor size still had a significant effect on CSS in NSCLC, although the effect seemed to be smaller than that in a more generalized population.

Keywords: non-small-cell lung cancer, tumor size, prognosis

\section{Introduction}

Tumor size is one of the main prognostic determinants that constitute the staging system for non-small-cell lung cancer (NSCLC). ${ }^{1}$ According to the most recent Eighth Edition of the Tumor, Node, and Metastasis (TNM) Classification of Lung Cancer, tumors $\leq 1 \mathrm{~cm}, 1-2 \mathrm{~cm}, 2-3 \mathrm{~cm}, 3-4 \mathrm{~cm}, 4-5 \mathrm{~cm}, 5-7 \mathrm{~cm}$, and $>7 \mathrm{~cm}$ are staged as T1a, T1b, T1c, T2a, T2b, T3, and T4, respectively. ${ }^{1}$ The prognostic value of tumor size has been demonstrated in pathologically early- and late-stage NSCLC. ${ }^{2-5}$

However, larger tumor size is associated with higher probability of lymph node metastasis and local disease extension (eg, mainstem bronchus involvement, visceral pleura invasion, chest wall invasion), which are both important prognostic factors and might confound the effect of large tumor size on prognosis. ${ }^{1}$ Although previous studies showed that large tumor size was a significant poor prognostic factor in nodenegative NSCLC, ${ }^{2,3}$ the number of lymph nodes examined was usually insufficient. A recent study of pathologic N0 NSCLC using the Surveillance, Epidemiology and End Results (SEER) database ${ }^{6}$ concluded that the lowest mortality risk occurred in those with 18-21 lymph nodes examined, while the median number of lymph nodes
Yihua Sun

Department of Thoracic Surgery, Fudan University Shanghai Cancer Center, 270 Dong-An Road, Shanghai 200032, People's Republic of China

Tel +862164175590

Fax +86 2I 6268 65II

Email hqchenI@yahoo.com;

sun_yihua76@hotmail.com 
examined was only 6 , suggesting that a proportion of reported "N0" NSCLC actually had missed lymph node metastasis, which contributed to the worse prognosis. It could be speculated that the probability of missed lymph node metastasis would be higher for larger tumors as tumor size was a positive predictor of lymph node involvement. In this study, we sought to determine the real effect of tumor size on survival outcomes in pN0 NSCLC with no local disease extension and sufficient lymph nodes examined (18 or more) using the SEER database.

\section{Methods}

This was a retrospective study using publicly available SEER data. Data were obtained through online access using the SEER*Stat software version 8.2.1-alpha. This study was conducted in line with the Helsinki Declaration. The Institutional Review Board of Fudan University Shanghai Cancer Center approved this study.

\section{Patient selection}

SEER database 1988-2012 submitted in November 2014 was used in this study. Inclusion criteria included the following: 1) patients were diagnosed from 1998 to 2012;2) the site code represented "Lung and Bronchus" (C34.0-C34.9); 3) Third Edition of International Classification of Diseases for Oncology (ICD-O-3) histology codes denoting NSCLC; 4 ) underwent lobectomy or more extended surgery (surgery codes $30-70)$; 5) 18 or more regional nodes examined; 6) no lymph node involvement or distant metastasis (N0M0); 7) tumors confined to one lung (extension code 10); 8) sufficient information on tumor size, overall survival (OS), and cancer-specific survival (CSS) available. We collected the following data: age at diagnosis, sex, race, year of diagnosis, status of surgery and radiation, tumor size, tumor histology, and information on OS and CSS. CSS was measured from the date of diagnosis to the date of death from lung cancer.

\section{Statistical analysis}

We treated tumor size as a categorical variable according to the Eighth Edition of the Tumor, Node, and Metastasis (TNM) Classification of Lung Cancer: T1a (0-10 mm), T1b (11-20 mm), T1c (21-30 mm), T2a (31-40 mm), T2b (41-50 mm), T3 (51-70 mm), and T4 (>70 mm). The Kaplan-Meier method with log-rank test was used to investigate the correlation between tumor size and survival outcomes in univariate analysis. Multivariate survival analysis to determine the independent prognostic effect was conducted using the Cox proportional-hazard model (forward stepwise selection with likelihood ratio test). Statistical analysis was performed in SPSS 16.0 (SPSS Inc., Chicago, IL, USA). All tests were two sided, and statistical significance was set as $P<0.05$.

\section{Results}

A total of 2,260 patients were included (Table 1). There were $1,136(50.3 \%)$ females and 1,124 (49.7\%) males, with a median age of 68 (range: 20-94) years. Sixty-seven $(3.0 \%)$ patients received radiation therapy. Tumor histology consisted of 1,322 (58.5\%) adenocarcinoma, 706 (31.2\%) squamous cell carcinoma, 64 (2.8\%) adenosquamous carcinoma, 93 (4.1\%) large cell carcinoma, and 75 (3.3\%) tumors with unspecified histology. According to tumor size, $123(5.4 \%)$ tumors were classified as T1a $(0-10 \mathrm{~mm})$, 707 (31.3\%) were T1b (11-20 mm), 592 (26.2\%) were T1c (21-30 mm), 364 (16.1\%) were T2a (31-40 mm), $186(8.2 \%)$ were T2b (41-50 mm), 179 (7.9\%) were T3 (51-70 mm), and $109(4.8 \%)$ were T4 $(>70 \mathrm{~mm})$.

Table I Characteristics of the included 2,260 patients with nonsmall-cell lung cancer

\begin{tabular}{ll}
\hline Variable & Number (\%) \\
\hline Age (years) & \\
$\leq 65$ & $878(38.8)$ \\
$>65$ & $1,382(61.2)$ \\
Sex & \\
Female & $\mathrm{I}, 136(50.3)$ \\
Male & $\mathrm{I}, 124(49.7)$ \\
Race & \\
White & $\mathrm{I}, 958(86.6)$ \\
Black & $160(7.1)$ \\
Others and unknown & $142(6.3)$ \\
Year of diagnosis & \\
I998-2004 & $710(3 \mathrm{I} .4)$ \\
$2005-20 I 2$ & $\mathrm{I}, 550(68.6)$ \\
Radiation & \\
Yes & $67(3.0)$ \\
No & $2,193(97.0)$ \\
Histology & \\
Adenocarcinoma & $\mathrm{I}, 322(58.5)$ \\
Squamous cell carcinoma & $706(31.2)$ \\
Adenosquamous carcinoma & $64(2.8)$ \\
Large cell carcinoma & $93(4.1)$ \\
NOS & $75(3.3)$ \\
Tumor size (mm) & \\
$0-10$ & $123(5.4)$ \\
II-20 & $707(31.3)$ \\
$2 I-30$ & $592(26.2)$ \\
$3 I-40$ & $364(16.1)$ \\
$4 I-50$ & $186(8.2)$ \\
$5 I-70$ & $179(7.9)$ \\
$>70$ & $109(4.8)$ \\
\hline
\end{tabular}

Abbreviation: NOS, not otherwise specified. 
The 5-year CSS rates for T1a, T1b, T1c, T2a, T2b, T3, and T4 patients were $85.6 \%, 84.4 \%, 79.9 \%, 77.9 \%, 70.0 \%$, $63.0 \%$, and $61.7 \%$, respectively (Figure 1). The 5-year OS rates for T1a, T1b, T1c, T2a, T2b, T3, and T4 patients were $77.8 \%, 74.1 \%, 68.2 \%, 64.5 \%, 58.7 \%, 53.2 \%$, and $57.3 \%$, respectively (Figure 2). Pairwise survival comparison showed that significant differences regarding CSS and OS were only found between T1b and T1c (both $P$-values were 0.004).

Multivariable survival analysis was further performed to estimate the effect of tumor size on survival outcomes after adjusting for other clinicopathologic variables (Table 2). Using T1a as the reference, the hazard ratio (HR) generally increased with tumor size in the analysis of CSS and OS, with the exception of $\mathrm{T} 4$ patients.

\section{Discussion}

Tumor size is an important prognostic factor in the Eighth Edition of the Tumor, Node, and Metastasis (TNM) Classification of Lung Cancer, especially in N0M0 cases. In a large-population study using the data submitted to the Cancer Research and Biostatistics, Rami-Porta et $\mathrm{al}^{1}$ found that the 5 -year OS rates of pathological N0M0R0 NSCLC $\leq 1 \mathrm{~cm}$,
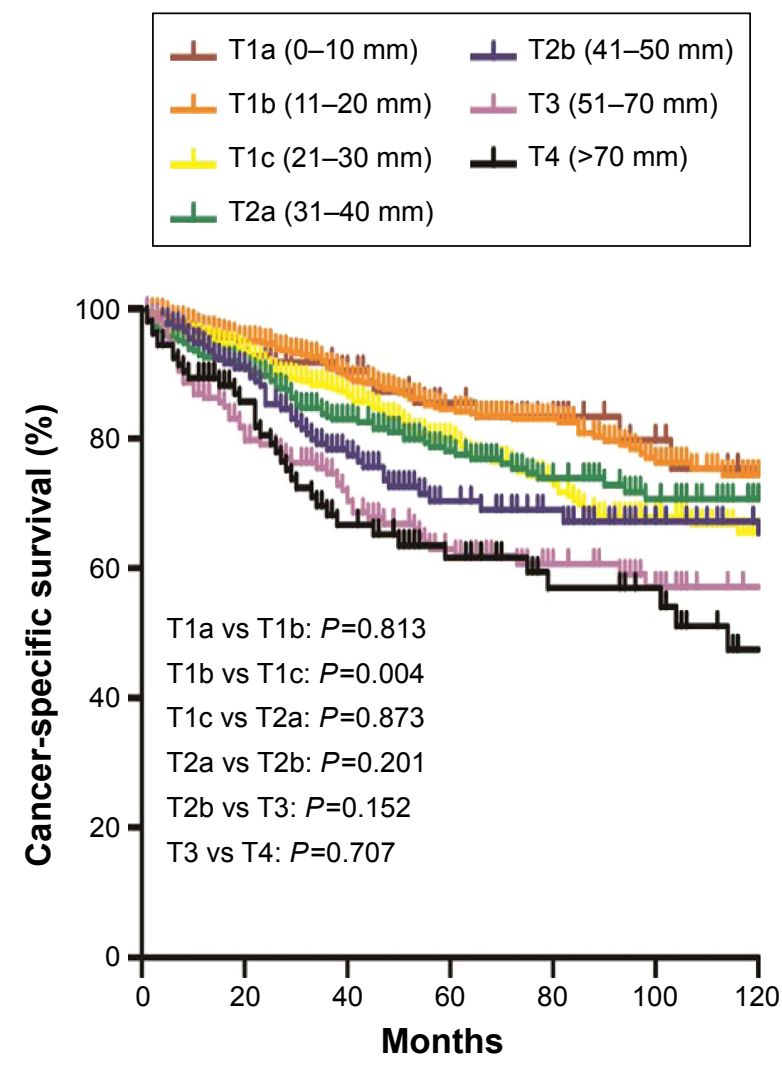

Figure I Cancer-specific survival of patients with T la $(0-10 \mathrm{~mm}), \mathrm{TI}$ (I I-20 mm), TIc $(2 \mathrm{I}-30 \mathrm{~mm}), \mathrm{T} 2 \mathrm{a}(3 \mathrm{I}-40 \mathrm{~mm}), \mathrm{T} 2 \mathrm{~b}(4 \mathrm{I}-50 \mathrm{~mm}), \mathrm{T} 3(5 \mathrm{I}-70 \mathrm{~mm})$, and T4 (>70 mm) non-small-cell lung cancer.
$1-2 \mathrm{~cm}, 2-3 \mathrm{~cm}, 3-4 \mathrm{~cm}, 4-5 \mathrm{~cm}, 5-7 \mathrm{~cm}$, and $>7 \mathrm{~cm}$ were $92 \%, 86 \%, 81 \%, 74 \%, 65 \%, 57 \%$, and $47 \%$, respectively. This study provided the basis for the revision of the $\mathrm{T}$ descriptors in the Eighth Edition of the Tumor, Node, and Metastasis (TNM) Classification of Lung Cancer. However, two factors might bias the actual effect of large tumor size on patient prognosis. First, large tumor size is associated with local disease extension, which also influences $\mathrm{T}$ staging. Another issue is the missed lymph node metastasis. A recent study based on SEER database found that in $\mathrm{pN} 0$ NSCLC, the lowest mortality risk occurred in those with 18-21 lymph nodes examined, while the median number of lymph nodes examined was only six. ${ }^{6}$ This result suggested that a proportion of the reported "pN0" NSCLC actually had missed lymph node metastasis. It is well demonstrated that large tumor size is associated with lymph node involvement. Therefore, the prognostic effect of large tumor size on $\mathrm{pN} 0$ NSCLC might be in part due to the high probability of missed lymph node metastasis. Furthermore, tumors that expanded to a large size but failed to metastasize to regional lymph nodes might be biologically indolent in essence, as suggested by some researchers. ${ }^{7,8}$

In this study, we investigated a large number of patients with N0M0 NSCLC who had no local extension and

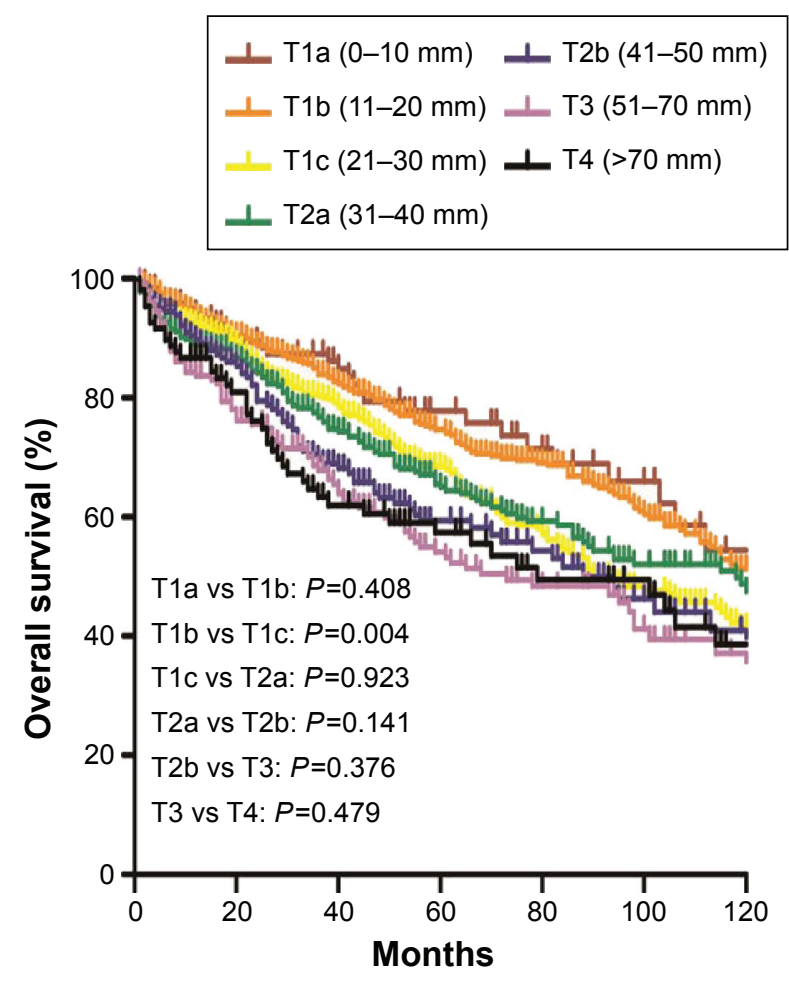

Figure 2 Overall survival of patients with Tla $(0-10 \mathrm{~mm})$, TIb $(I \mathrm{I}-20 \mathrm{~mm})$, TIc (2I-30 mm), T2a (3I-40 mm), T2b (4I-50 mm), T3 (5I-70 mm), and T4 (>70 mm) non-small-cell lung cancer. 
Table 2 Effect of tumor size on cancer-specific survival and overall survival in multivariate survival analysis

\begin{tabular}{|c|c|c|c|c|}
\hline \multirow{2}{*}{$\begin{array}{l}\text { Tumor } \\
\text { size }(\mathbf{m m})\end{array}$} & \multicolumn{2}{|c|}{ Cancer-specific survival } & \multicolumn{2}{|l|}{ Overall survival } \\
\hline & HR (95\% Cl) & $P$-value & HR (95\% Cl) & $P$-value \\
\hline $0-10$ & 1.000 (Reference) & & I.000 (Reference) & \\
\hline $11-20$ & $1.072(0.630-1.824)$ & 0.799 & I.I52 (0.778-I.707) & 0.479 \\
\hline $21-30$ & $1.510(0.893-2.551)$ & 0.124 & $1.469(0.995-2.171)$ & 0.053 \\
\hline $31-40$ & I.49| (0.866-2.566) & 0.149 & $1.417(0.946-2.122)$ & 0.091 \\
\hline $4 I-50$ & $1.870(1.056-3.314)$ & 0.032 & $1.656(1.078-2.545)$ & 0.021 \\
\hline $5 I-70$ & $2.203(1.260-3.850)$ & 0.006 & $1.733(1.133-2.649)$ & 0.011 \\
\hline$>70$ & 1.885 (1.028-3.459) & 0.040 & $1.324(0.819-2.140)$ & 0.252 \\
\hline
\end{tabular}

Abbreviations: $\mathrm{HR}$, hazard ratio; $\mathrm{Cl}$, confidence interval.

underwent complete lymph node examination (18 or more nodes). We believed this cohort of patients better reflected the true effect of tumor size on patient prognosis. The 5-year OS rates for T1a, T1b, T1c, T2a, T2b, T3, and T4 patients were $77.8 \%, 74.1 \%, 68.2 \%, 64.5 \%, 58.7 \%, 53.2 \%$, and $57.3 \%$, respectively. Our results revealed a significant trend toward worse survival with increasing tumor size. However, compared to the study by Rami-Porta et al, ${ }^{1}$ the difference in survival between patients with large and small tumors in our study was much smaller. For example, in their study, the 5 -year OS rate decreased from $92 \%$ in T1a patients to $47 \%$ in $\mathrm{T} 4$ patients, whereas in our study, the 5 -year OS rate dropped from $77.8 \%$ to $57.3 \%$. We believe that when the effect of missed lymph node metastasis and local tumor extension had been adjusted, the effect of large tumor size on prognosis of NO NSCLC was not that large as we previously considered.

Multivariate survival analysis further proved the independent prognostic value of tumor size. However, using T1a $(0-10 \mathrm{~mm})$ as the reference, we found that HR did not increase when tumor size had reached $50 \mathrm{~mm}$. We hypothesize that there are two effects on distant metastasis as tumors grow larger: one is the malignant cellular expansion, which contributed to metastasis; the other is that in tumors that do not metastasize to regional lymph nodes, large tumor size might indicate an indolent phenotype. The former effect might be more prevalent in tumors $<5 \mathrm{~cm}$, while the latter effect plays a more important role when tumor size reaches $5 \mathrm{~cm}$.

There are several limitations in this study. First, the definition of "sufficient lymph node examination" was arbitrary, although it was based on a previous study. ${ }^{6} \mathrm{We}$ believed that with more lymph nodes retrieved, the bias caused by missed lymph node metastasis would be reduced. Second, although we limited the study to patients who underwent lobectomy or more extended surgeries, some important treatment information such as adjuvant chemotherapy was not available in the SEER database.

\section{Conclusion}

In conclusion, after adjusting for lymph node examination and disease extension, tumor size still had a significant effect on poor prognosis in NSCLC, although the effect seemed to be smaller than that in a more generalized population. Hopefully, our results will serve as a framework to encourage further studies to determine the actual prognostic effects of tumor size.

\section{Author contributions}

YZ designed this study, collected and analyzed data, and wrote the main manuscript. HC and YS designed and directed the overall project. All authors contributed toward data analysis, drafting and critically revising the paper and agree to be accountable for all aspects of the work.

\section{Disclosure}

The authors report no conflicts of interest in this work.

\section{References}

1. Rami-Porta R, Bolejack V, Crowley J, et al; IASLC Staging and Prognostic Factors Committee, Advisory Boards and Participating Institutions. The IASLC lung cancer staging project: proposals for the revisions of the $\mathrm{T}$ descriptors in the forthcoming eighth edition of the TNM classification for lung cancer. J Thorac Oncol. 2015;10(7):990-1003.

2. Zhang J, Gold KA, Lin HY, et al. Relationship between tumor size and survival in non-small-cell lung cancer (NSCLC): an analysis of the surveillance, epidemiology, and end results (SEER) registry. $J$ Thorac Oncol. 2015;10(4):682-690.

3. Rami-Porta R, Ball D, Crowley J, et al; International Staging Committee; Cancer Research and Biostatistics; Observers to the Committee; Participating Institutions. The IASLC lung cancer staging project: proposals for the revision of the $\mathrm{T}$ descriptors in the forthcoming (seventh) edition of the TNM classification for lung cancer. $J$ Thorac Oncol. 2007;2(7):593-602.

4. Maximus S, Nguyen DV, Mu Y, Calhoun RF, Cooke DT. Size of stage IIIA primary lung cancers and survival: a surveillance, epidemiology and end results database analysis. Am Surg. 2012;78(11):1232-1237.

5. Morgensztern D, Waqar S, Subramanian J, Gao F, Trinkaus K, Govindan R. Prognostic significance of tumor size in patients with stage III non-smallcell lung cancer: a surveillance, epidemiology, and end results (SEER) survey from 1998 to 2003. J Thorac Oncol. 2012;7(10):1479-1484.

6. Osarogiagbon RU, Ogbata O, Yu X. Number of lymph nodes associated with maximal reduction of long-term mortality risk in pathologic node-negative non-small cell lung cancer. Ann Thorac Surg. 2014;97(2): 385-393. 
7. Patz EF Jr, Rossi S, Harpole DH Jr, Herndon JE, Goodman PC. Correlation of tumor size and survival in patients with stage IA non-small cell lung cancer. Chest. 2000;117(6):1568-1571.
8. Black WC. Unexpected observations on tumor size and survival in stage IA non-small cell lung cancer. Chest. 2000;117(6):1532-1534.

\section{Publish your work in this journal}

OncoTargets and Therapy is an international, peer-reviewed, open access journal focusing on the pathological basis of all cancers, potential targets for therapy and treatment protocols employed to improve the management of cancer patients. The journal also focuses on the impact of management programs and new therapeutic agents and protocols on

\section{Dovepress}

patient perspectives such as quality of life, adherence and satisfaction. The manuscript management system is completely online and includes a very quick and fair peer-review system, which is all easy to use. Visit http://www.dovepress.com/testimonials.php to read real quotes from published authors.

Submit your manuscript here: http://www.dovepress.com/oncotargets-and-therapy-journal 